OPEN ACCESS

Edited by:

Jeremy Teoh,

The Chinese University of Hong

Kong, China

Reviewed by:

Daniele Castellani,

Polytechnic University of $L e$

Marche, Italy

Mohamad Moussa,

Lebanese University, Lebanon

*Correspondence:

Hugh Mostafid

Hugh.Mostafid@nhs.net

Specialty section

This article was submitted to

Genitourinary Surgery,

a section of the journal

Frontiers in Surgery

Received: 25 March 2021 Accepted: 30 April 2021 Published: 31 May 2021

Citation:

Fankhauser CD, Wettstein MS,

Afferi L, Grossmann NC and

Mostafid H (2021) En Bloc Resection

of Bladder Tumor-Is it the Way

Forward? Front. Surg. 8:685506.

doi: 10.3389/fsurg.2021.685506

\section{En Bloc Resection of Bladder Tumor-Is It the Way Forward?}

\author{
Christian Daniel Fankhauser ${ }^{1}$, Marian Severin Wettstein ${ }^{2}$, Luca Afferi ${ }^{1}$, \\ Nico Christian Grossmann ${ }^{2}$ and Hugh Mostafid ${ }^{3 *}$
}

' Department of Urology, Luzerner Kantonsspital, Luzern, Switzerland, ${ }^{2}$ Department of Urology, University of Zurich, Zurich, Switzerland, ${ }^{3}$ Department of Urology, Royal Surrey County Hospital, Guildford, United Kingdom

Transurethral resection of bladder tumors (TURBT) represents the cornerstone in diagnosis and treatment of bladder cancer but recurrence is observed in up to $80 \%$ and over- or understaging with TURBT is common. A more recent development to overcome these limitations represents en-bloc resection of bladder tumors (ERBT) which offers several advantages over TURBT. In this report, we briefly review studies assessing outcomes of bladder cancer patients undergoing ERBT. Most randomized and nonrandomized trial demonstrate improvement in clinical outcomes for ERBT over TURBT, however more pathological and translational studies are warranted.

Keywords: trans-urethral resection of bladder tumor, bladder cancer, transurethral, urothelial atypia, urothelial cancer

\section{INTRODUCTION}

Bladder cancer has an estimated 429,793 new diagnoses leading to 165,084 deaths per year worldwide (1) but with a globally wide variation (2). For example in the European Union, an increase by $41 \%$ from currently 124188 up to 174891 new cases per year is expected by the year 2035 (1). Patients with non-muscle invasive bladder cancer (NMIBC) require lifetime surveillance with cystoscopy and imaging. Due to the high recurrence-rate of up to $80 \%$ and related re-treatment, lifetime treatment costs are among the highest of all cancers, ranging from $\$ 100,000$ to $\$ 200,000$ per patient in the United States (3). This significant financial burden on the population and healthcare system calls for effective bladder cancer diagnostics and treatment.

Transurethral resection of bladder tumors (TURBT) represents the cornerstone in diagnosis and treatment of bladder cancer since the 1940s. Aims of TURBT include symptom relief, histological diagnosis (grade, stage, variant histology) and cure in some stages of NMIBC. Several technological advantages including bipolar TURBT have been introduced (4). However, both mono- and bipolar TURBT represent a piecemeal resection of the tumor with the risk of tumor seeding and over- and under staging because of tangential sectioning and thermal artifacts (5). This resection method ignores basic principle of oncological surgery being resection in one specimen instead of scattering malignant cells. To decrease the high recurrence rates, several new methodologies have been developed to allow en bloc removal of bladder cancers, for example in 1980 snare polypectomy a method which did not allow complete resection of the bladder base (6).

Complete en-bloc resection including the bladder base was only achieved after the introduction of en-bloc resection techniques as described in 1997 by Kawada et al. using a new arched resection loop (7). Later, the same approach but using a standard mono- or bipolar loop electrode or laser fibers have been introduced. A recent consensus agreed that any method "removing the bladder tumor in one piece" can be described as en-bloc transurethral resection of bladder tumors (ERBT) (8). All ERBT techniques have three assumed advantages. First, the histological assessment may be facilitated by en-bloc resection. Second, remaining in the same surgical plain may decrease 
complications. Third, avoiding tumor fragmentation may decrease the tumor spillage and improve oncological outcomes. In this report, we review studies assessing outcomes of patients with bladder cancer undergoing ERBT.

In the most recent and comprehensive systematic review and meta-analysis, Teoh et al. identified 10 randomized controlled trials comparing ERBT with TURBT (8). Limitations of those trials included low individual sample size as well as heterogeneity in outcome reporting and treatment (e.g., energy source used, postoperative management). Nevertheless, this meta-analysis represents the best available evidence and the authors concluded that compared to TURBT, ERBT has a longer operation time but shorter irrigation time and lower risk of bladder perforation. However, this meta-analysis of randomized trials was not able to show a difference regarding catheterization time, hospital stay, occurrence of obturator nerve reflex, presence of detrusor muscle in specimen or recurrence rates. Two more recent randomized trials were not included in the review. The first compared classical TURBT with ERBT using hydrodissection, both assisted by photodynamic diagnosis using hexaminolevulinate (HAL), and reported a higher percentage of presence of detrusor muscle in specimen in the en-bloc group (86 vs. 63\%) (9). The second compared TURBT with holmium laser ERBT and reported a higher rate of post-operative epirubicin instillations, shorter time to catheter removal and hospital stay with a higher percentage of presence of detrusor muscle, fewer cautery artifacts and residual tumor in the pathological specimen but no difference in recurrence free survival (10).

In the same systematic review, the authors also compared the results of 22 non-randomized trials with similar findings regarding irrigation time and bladder perforation rates but discordant and more favorable results for ERBT regarding catheterization time, hospital stay, occurrence of obturator nerve reflex, presence of detrusor muscle in specimen and recurrence rates. Those findings are in line with similar studies which were published more recently and were therefore not included in the systematic review (11-14). Additionally, the authors performed a Delphi consensus and reached consensus that ERBT can be attempted in patients with $<4$ bladder tumors with a tumor size $<3 \mathrm{~cm}$. Consensus was also reached in other key areas including the statement that marking of the

\section{REFERENCES}

1. Ferlay JSH, Bray F, Forman D, Mathers C, Parkin DM. GLOBOCAN 2012, Cancer Incidence and Mortality Worldwide. Lyon: International Agency for Research on Cancer (2012). Available online at: http://globocan.iarc.fr (accessed August 9, 2017).

2. Teoh JY, Huang J, Ko WY, Lok V, Choi P, Ng CF, et al. Global trends of bladder cancer incidence and mortality, and their associations with tobacco use and gross domestic product per capita. Eur Urol. (2020) 78:893-906. doi: 10.1016/j.eururo.2020.09.006

3. Botteman MF, Pashos CL, Redaelli A, Laskin B, Hauser R. The health economics of bladder cancer. Pharmaco Economics. (2003) 21:1315-30. doi: 10.1007/BF03262330

4. Teoh JY, Chan ES, Yip SY, Tam HM, Chiu PK, Yee CH, et al. Comparison of detrusor muscle sampling rate in monopolar and bipolar transurethral planned circumferential margin at least $5 \mathrm{~mm}$ from any visible bladder tumor before starting the resection is recommended. In order to assess the feasibility of ERBT in routine practice the same authors implemented ERBT as the primary surgical approach in all NMIBC patients with TURBT reserved as a conversion procedure in those patients where ERBT could not be completed for technical reasons. The authors found that ERBT was successfully carried out in $73 \%$ of all patients including those with large and multi-focal tumors, and $84 \%$ in patients with bladder tumors of $\leq 3 \mathrm{~cm}$ confirming that ERBT could be used as the primary approach for excising bladder tumor in the majority of NMIBC patients (15).

Whereas, direct improvements of certain clinical outcomes by ERBT are suggested by numerous clinical studies, pathological and translational studies are limited. First pathology studies suggested a higher interobserver concordance and time for analysis for ERBT specimens compared to TURBT (16) and the potential for improved sub staging in T1 disease (17). A second translational study reported a higher level of circulating tumor cells after TURBT compared to ERBT (18). Whilst the technique of ERBT has been relatively standardized irrespective of energy source used, the major current limitation of ERBT remains extraction of large en-bloc specimens, generally $>3 \mathrm{~cm}$. A number of techniques have been described such as the use of an Endo-catch specimen retrieval bag. Such challenges could be overcome fairly easily with collaboration from endoscopic equipment manufacturers (19).

In summary, en-bloc TURBT seem to be comparable or superior in most outcomes compared to classical TURBT and those results seem to be compelling for many urologists. A recent survey among 200 European urologists which reported that en-bloc TURBT is already the resection technique of choice in $35 \%$ of cases (20). Further development and studies of this technique are warranted.

\section{AUTHOR CONTRIBUTIONS}

CF and HM: manuscript drafting and literature review. LA, MW, and NG: critical revision of manuscript. All authors contributed to the article and approved the submitted version. resection of bladder tumor: a randomized trial. Annals Surg Oncol. (2017) 24:1428-34. doi: 10.1245/s10434-016-5700-7

5. Hansel DE, Amin MB, Comperat E, Cote RJ, Knüchel R, Montironi R, et al. A contemporary update on pathology standards for bladder cancer: transurethral resection and radical cystectomy specimens. Eur Urol. (2013) 63:321-32. doi: 10.1016/j.eururo.2012.10.008

6. Kitamura K, Kataoka K, Fujioka H, Kashiwai K. Transurethral resection of a bladder tumor by the use of a polypectomy snare. J Urol. (1980) 124:806-7. doi: 10.1016/S0022-5347(17)55675-X

7. Kawada T, Ebihara K, Suzuki T, Imai K, Yamanaka H. A new technique for transurethral resection of bladder tumors: rotational tumor resection using a new arched electrode. J Urol. (1997) 157:2225-6. doi: 10.1016/S0022-5347(01)64724-4

8. Teoh JY, MacLennan S, Chan VW, Miki J, Lee HY, Chiong E, et al. An international collaborative consensus statement on en bloc resection 
of bladder tumour incorporating two systematic reviews, a two-round delphi survey, and a consensus meeting. Eur Urol. (2020) 78:546-69. doi: 10.1016/j.eururo.2020.04.059

9. Gakis G, Karl A, Bertz S, Burger M, Fritsche HM, Hartmann A, et al. Transurethral en bloc submucosal hydrodissection vs conventional resection for resection of non-muscle-invasive bladder cancer (HYBRIDBLUE): a randomised, multicentre trial. BJU Int. (2020) 126:509-19. doi: 10.1111/bju.15150

10. Hashem A, Mosbah A, El-Tabey NA, Laymon M, Ibrahiem E-H, Abd Elhamid $\mathrm{M}$, et al. Holmium laser en-bloc resection versus conventional transurethral resection of bladder tumors for treatment of non-muscleinvasive bladder cancer: a randomized clinical trial. Eur Urol Focus. (2020). doi: 10.1016/j.euf.2020.12.003. [Epub ahead of print].

11. Li s, Jia Y, Yu C, Xiao H, Guo L, Sun F, et al. Influences of different operative methods on the recurrence rate of non-muscle-invasive bladder cancer. Urol J. (2020) 16:5965. doi: 10.22037/uj.v16i7.5965

12. Muralidharan K, Ansari AA, Naidu B. A retrospective \& prospective study to know that en-bloc TURBT for non-muscle invasive bladder carcinoma better than conventional TURBT in terms of tumor recurrence and tumor progression in South Indian. Int J Surg. (2020) 4:435-9. doi: 10.33545/surgery.2020.v4.i1h.381

13. Poletajew S, Krajewski W, Stelmach P, Adamowicz J, Nowak $€$, Moschini M, et al. En-bloc resection of urinary bladder tumour a prospective controlled multicentre observational study. Wideochir Inne Tech Maloinwazyjne. (2021) 16:145-50. doi: 10.5114/wiitm.2020. 95399

14. Enikeev D, Taratkin M, Laukhtina E, Sukhanov R, Dymov A, Sorokin $\mathrm{N}$, et al. V12-03 SAFETY AND SHORT-TERM ONCOLOGICAL OUTCOMES OF THULIUM FIBER LASER EN-BLOC RESECTION OF NON-MUSCLE-INVASIVE BLADDER CANCER: A PROSPECTIVE NONRANDOMIZED PHASE II TRIAL. J Urol. (2020) 203(Suppl. 4):e1110-1. doi: 10.1097/JU.0000000000000957.03

15. Teoh J, Mayor N, Li K, Lo K, Ng C, Mostafid H. En-bloc resection of bladder tumour as primary treatment for patients with non-muscleinvasive bladder cancer: Routine implementation in a multi-centre setting. World J Urol. (2021). doi: 10.1007/s00345-021-03675-9. [Epub ahead of print].

16. Yanagisawa T, Yorozu T, Miki J, Iwatani K, Obayashi K, Sato S, et al. Feasibility and accuracy of pathological diagnosis in en bloc resection versus conventional transurethral resection of bladder tumor: evaluation with pT1 sub-staging by 10 pathologists. Histopathology. (2020) 205:1622-28. doi: 10.1111/his.14307

17. Yanagisawa T, Miki J, Yorozu T, Iwatani K, Obayashi K, Sato S, et al. Vertical lamina propria invasion diagnosed by en bloc transurethral resection is a significant predictor of progression for pT1 bladder cancer. J Urol. (2021) 205:1622-28. doi: 10.1097/JU.0000000000001630

18. Huang H, Wang T, Ahmed MG, Zhu L, Yang C, Li W, et al. Retrograde en bloc resection for non-muscle invasive bladder tumor can reduce the risk of seeding cancer cells into the peripheral circulation. World J Surg Oncol. (2020) 18:33. doi: 10.1186/s12957-020-1808-0

19. Mostafid H, Babjuk M, Bochner B, Lerner SP, Witjes F, Palou J, et al. Transurethral resection of bladder tumour: the neglected procedure in the technology race in bladder cancer. Eur Urol. (2020) 77:669-70. doi: 10.1016/j.eururo.2020.03.005

20. Waldbillig F, Hein S, Grüne B, Suarez-Ibarrola R, Liatsikos E, Salomon G, et al. Current European trends in endoscopic imaging and transurethral resection of bladder tumors. J Endourol. (2020) 34:312-21. doi: 10.1089/end.2019.0651

Conflict of Interest: The authors declare that the research was conducted in the absence of any commercial or financial relationships that could be construed as a potential conflict of interest.

Copyright (c) 2021 Fankhauser, Wettstein, Afferi, Grossmann and Mostafid. This is an open-access article distributed under the terms of the Creative Commons Attribution License (CC BY). The use, distribution or reproduction in other forums is permitted, provided the original author(s) and the copyright owner(s) are credited and that the original publication in this journal is cited, in accordance with accepted academic practice. No use, distribution or reproduction is permitted which does not comply with these terms. 